This document is the Accepted Manuscript version of a Published Work that appeared in final form in Green Chem., copyright (C) The Royal Society of Chemistry 2016 after peer review and technical editing by the publisher. To access the final edited and published work see: http://dx.doi.org/10.1039/c6gc00894a.

\title{
Glycerol oxidehydration to pyruvaldehyde over silver-based catalysts for improved lactic acid production $\dagger$
}

\author{
G. M. Lari, ${ }^{a}$ R. García-Muelas, ${ }^{b}$ C. Mondelli, ${ }^{* a}$ N. López ${ }^{b}$ and J. Pérez-Ramírez ${ }^{\star^{a}}$
}

Sustainable technologies for the valorisation of the burgeoning amounts of glycerol (GLY) obtained as waste in the production of biodiesel are increasingly sought after. Its conversion into lactic acid (LA) is appealing due to the versatility of this platform chemical and its high added value. Here, we introduce Ag-based catalysts for the oxidehydration of GLY to pyruvaldehyde (PAl) and demonstrate the superiority of this compound in comparison to dihydroxyacetone (DHA) as the intermediate of an alternative two-step GLY-to-LA process. Evaluation of various metals and carriers identified $\mathrm{Ag} / \mathrm{Al}_{2} \mathrm{O}_{3}$ as the best performer for PAl production. This was rationalised based on the optimal redox potential of the metal and the high concentration of Lewis-acid sites and the limited Brønsted acidity of the support. At $623 \mathrm{~K}$ and $\mathrm{O}_{2} / \mathrm{GLY}=$ 0.5 , a PAl yield of $80 \%$ was attained, which remained stable for $24 \mathrm{~h}$. Characterisation of the used catalyst indicated that the surface of the silver nanoparticles was partially oxidised upon reaction. Density functional theory (DFT) modelling revealed that the oxidation of acetol obtained from GLY after the initial dehydration step is kinetically and thermodynamically favoured on a partially oxidised silver surface $\left(\mathrm{AgO}_{x} / \mathrm{Ag}\right)$ compared to metallic (Ag) or fully oxidic $\left(\mathrm{Ag}_{2} \mathrm{O}\right)$ ones. Finally, we show that PAl can be isomerised into LA and methyl lactate over Sn-containing zeolites with the same rates as DHA but at a $40 \mathrm{~K}$ lower temperature (343 vs. $383 \mathrm{~K}$ ). This not only allows for energy savings but also for a remarkably increased catalyst stability.

\section{Introduction}

Lactic acid (LA) has been recognised as a primary biobased platform molecule, in view of its multiple applications in the healthcare and food industries and its use in the production of acrylates and biodegradable and biocompatible polymers. ${ }^{1}$ Especially due to the increasing prominence of polylactic acid, which is replacing polyethylene terephthalate (PET) in a growing number of uses, ${ }^{2}$ the annual demand for LA is expected to increase to $6 \times 10^{5}$ ton by 2020 . $^{3}$ The current man-

\footnotetext{
${ }^{a}$ Institute for Chemical and Bioengineering, Department of Chemistry and Applied Biosciences, ETH Zurich, Vladimir-Prelog-Weg 1, CH-8093 Zurich, Switzerland. E-mail: cecilia.mondelli@chem.ethz.ch,jpr@chem.ethz.ch

${ }^{b}$ Institute of Chemical Research of Catalonia, ICIQ, The Barcelona Institute of Science and Technology, Av. Països Catalans 16, ES-43007 Tarragona, Spain $\dagger$ Electronic supplementary information (ESI) available: Density of states and calculated core-level shifts (Ag 3d) for the three silver surfaces modelled, characterisation data of the supports, the Sn-containing zeolites and an Ag-based catalyst, tabulated initial conversion and selectivity data for the glycerol oxidehydration and acetol dehydrogenation reactions, selectivity to pyruvaldehyde as a function of the concentration of Brønsted-acid sites in the best Ag-based catalyst, energy profiles for the regeneration of $\mathrm{Ag}_{2} \mathrm{O}$ and $\mathrm{AgO}_{x} / \mathrm{Ag}$ surfaces and representation of the additionally considered $\mathrm{Ag}_{2} \mathrm{O} / \mathrm{Ag}$ surface and energy profiles for the reaction over this surface and for its regeneration. Structures from the DFT calculations are freely available at http://dx.doi.org/10.19061/iochem-bd-1-8. See DOI: $10.1039 / \mathrm{c} 6 g \mathrm{c} 00894 \mathrm{a}$
}

ufacture route, based on the fermentation of sugars, seems unable to sustain such a large market, due to its low productivity and the stoichiometric amount of gypsum generated as waste. ${ }^{3}$ The application of electrodialysis membranes to split the salts avoiding the addition of sulphuric acid or the engineering of yeasts able to withstand solutions with lower $\mathrm{pH}$ have been proposed to address the latter issue, ${ }^{4}$ but the low sugar concentration of the fermentation broth remains a limiting factor of the biocatalytic technology. For this reason, alternative pathways enabling a large-scale, economically and environmentally-friendly production of LA are demanded. One of the most promising strategies in this direction comprises the conversion of glycerol (GLY) through oxidation to dihydroxyacetone (DHA) followed by isomerisation. ${ }^{5}$ The triol is obtained as a byproduct in the preparation of biodiesel in growing amounts and its very low price justifies its purification to serve as feedstock for the preparation of added-value chemicals. ${ }^{6}$ The conversion of glycerol into lactic acid has been conducted either in one pot over $\mathrm{Au} / \mathrm{CeO}_{2}, \mathrm{Au}-\mathrm{Pt} / \mathrm{TiO}_{2}$ and $\mathrm{Pt} / \mathrm{Sn}-\mathrm{MFI}$ catalysts ${ }^{7}$ or in two separate steps, using an enzyme or an iron-containing zeolite in the first reaction ${ }^{8}$ and Lewis acids for the second. ${ }^{9}$ Zeolites containing tin atoms in framework positions are superior catalysts for DHA isomerisation, ${ }^{10}$ which involves the dehydration of DHA to pyruvaldehyde (PAl), followed by the addition of a solvent (i.e., water or alcohol) molecule and a 

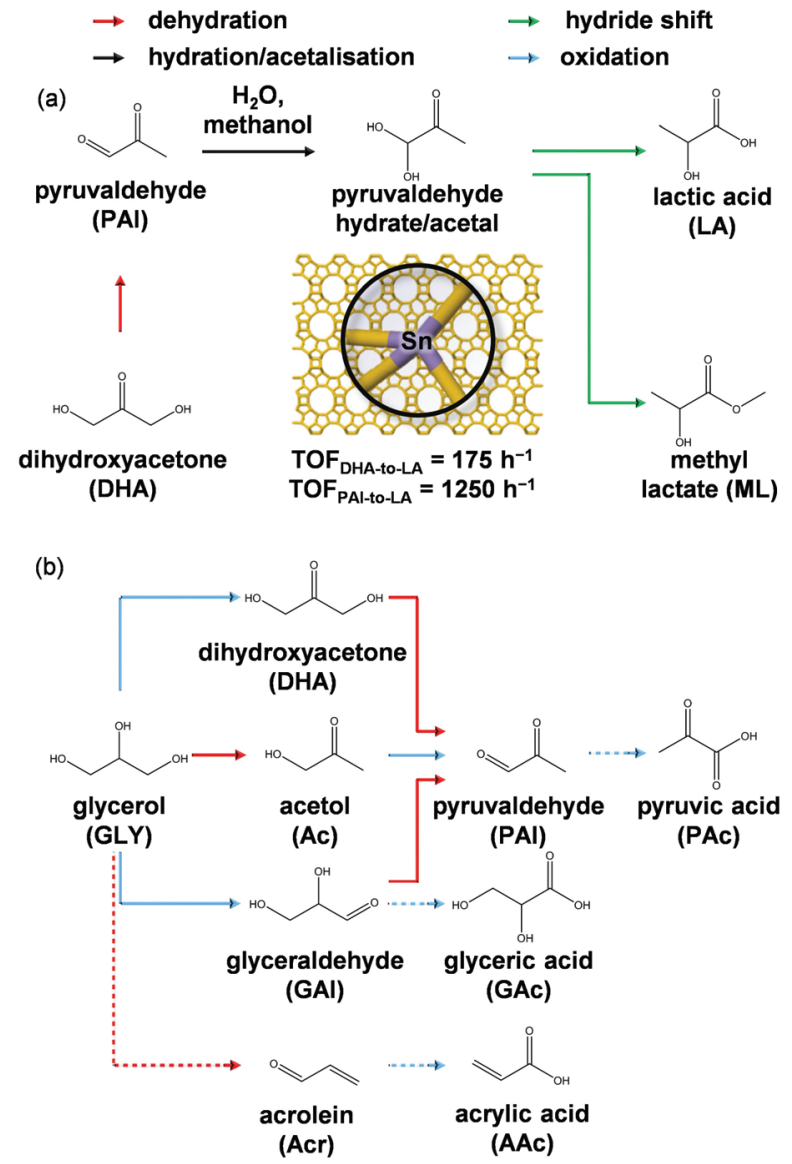

Scheme 1 (a) Steps involved in the liquid-phase isomerisation of DHA to LA in water or methanol and (b) reaction network envisaged for the gas-phase conversion of GLY to PAl. The dashed arrows identify competitive oxidation and dehydration pathways.

1,2-hydride shift (Scheme 1a). ${ }^{11}$ Kinetic studies demonstrated that the overall rate is determined by the dehydration step, ${ }^{11}$ and that the direct conversion of PAl is up to one order of magnitude faster than that of DHA under the same conditions. ${ }^{12}$ Based on these observations, an alternative process with PAl as the intermediate would be advantageous to diminish the mass of catalyst or the temperature applied to the isomerisation step. Most importantly, milder conditions are expected to minimise one of the biggest drawbacks of the stannosilicates, i.e., their fast deactivation under continuous-flow operation. ${ }^{12}$ In this respect, it has been shown that the hydrothermal stability of zeolites increases at lower temperatures ${ }^{13}$ and the highly oxygenated reactant and intermediates are less prone to condensation reactions leading to fouling. ${ }^{14}$

The selective conversion of GLY to PAl has been scarcely investigated. A patent reported the activity of transition metals, comprising vanadium, molybdenum, copper, silver and tin, supported onto an aluminosilicate. ${ }^{15}$ Additionally, PAl has been observed as a byproduct in the liquid-phase conversion of GLY under oxidising conditions ${ }^{16}$ and in its gas-phase oxidative upgrading to DHA or acrylic acid (AAc), respectively. ${ }^{8 b, 17}$ It has been noted that the coexistence of redox and
Lewis-acid sites favours the formation of PAl by oxidationdehydration (oxidehydration), but there is limited information on the reaction pathway (Scheme $1 b$ ) and the exact nature of the two functionalities.

Herein, we evaluate different metals and carriers used in oxidation and dehydration reactions, respectively, identifying silver supported on alumina as an efficient system for the gasphase production of PAl from GLY. Its superiority is explained based on the optimal redox potential of the active phase and the Lewis acidity of the oxide. Additionally, we assess the impact of the reaction conditions and study the stability of the best-performing catalyst. The dehydrogenation mechanism and the chemical state of the surface are unravelled by combining DFT simulations and in-depth catalyst characterisation. Finally, the benefits of using PAl as the intermediate in the novel GLY-to-LA process are shown by confronting the longterm stability of Sn-containing zeolites in the conversion of $\mathrm{PAl}$ and DHA in water and methanol.

\section{Experimental}

\section{Catalyst preparation}

Supported metal catalysts. Supported catalysts containing $5 \mathrm{wt} \%$ of $\mathrm{V}, \mathrm{Ni}, \mathrm{Fe}, \mathrm{Sn}, \mathrm{Cu}, \mathrm{Ru}, \mathrm{Ag}$, Pd or Pt were prepared by dry impregnation of $\gamma$-alumina (Alfa Aesar, 42 576, 99.997\%, labelled as $\mathrm{Al}_{2} \mathrm{O}_{3}$-a) using $\mathrm{NH}_{4} \mathrm{VNO}_{3}$ (Fluka, >99\%), $\mathrm{NiCl}_{2} \cdot 6 \mathrm{H}_{2} \mathrm{O}$ (Alfa Aesar, 99.95\%), $\mathrm{Fe}\left(\mathrm{NO}_{3}\right)_{3} \cdot 9 \mathrm{H}_{2} \mathrm{O}$ (Sigma-Aldrich, >98\%), $\mathrm{SnSO}_{4} \quad$ (ABCR, 95\%), $\mathrm{Cu}\left(\mathrm{NO}_{3}\right)_{2} \cdot 3 \mathrm{H}_{2} \mathrm{O}$ (Sigma-Aldrich, 98-103\%), $\mathrm{RuCl}_{3} \cdot x \mathrm{H}_{2} \mathrm{O}$ (ABCR, 99.9\%), $\mathrm{AgNO}_{3}$ (ABCR, 99.9\%), $\mathrm{Pd}\left(\mathrm{NO}_{3}\right)_{2} \cdot x \mathrm{H}_{2} \mathrm{O}$ (ABCR, 99.9\%), $\mathrm{H}_{2} \mathrm{PtCl}_{6}$ (Sigma-Aldrich, $8 \mathrm{wt} \%$ water solution) and $\mathrm{HAuCl}_{4} \cdot 3 \mathrm{H}_{2} \mathrm{O}(\mathrm{ABCR}, 99.99 \%)$ as the metal precursors. An aliquot of the salt (corresponding to $0.05 \mathrm{~g}$ of the metal) was dissolved in deionised water $\left(0.50 \mathrm{~cm}^{3}\right)$ and the solution was added to $0.95 \mathrm{~g}$ of the dried support. The wet powder was mixed for $5 \mathrm{~min}$ and freeze-dried at $3 \times 10^{-4} \mathrm{bar}$ for $16 \mathrm{~h}$. Additional catalysts containing $5 \mathrm{wt} \% \mathrm{Ag}$ were obtained following the same procedure using zeolites with MFI framework and a nominal $\mathrm{Si} / \mathrm{Al}$ ratio of 40 (Zeolyst, CBV8014, denoted as Z40) or 940 (Tosoh Corp., HSZ-8090H0A, denoted as Z940), other $\gamma$-aluminas (Sigma-Aldrich, acidic, basic and neutral, Brokmann grade $\mathrm{I}$, labelled as $\mathrm{Al}_{2} \mathrm{O}_{3}-\mathrm{b}$, $\mathrm{Al}_{2} \mathrm{O}_{3}-\mathrm{c}$ and $\mathrm{Al}_{2} \mathrm{O}_{3}-\mathrm{d}$, respectively), silica (Evonik, Sipernat 120), amorphous silica-alumina (Sigma-Aldrich, grade 135) and silicon carbide (Sigma-Aldrich, particle size $<100 \mathrm{~nm}$ ) as carriers. Finally, a large batch (ca. $50 \mathrm{~g}$ ) of $5 \mathrm{wt} \% \mathrm{Ag} / \mathrm{Al}_{2} \mathrm{O}_{3}$-a was prepared by spray deposition ${ }^{18}$ using a Büchi Mini Spray Dryer B-290. Silver nitrate (3.95 g) was dissolved in deionised water $\left(500 \mathrm{~cm}^{3}\right)$ under magnetic stirring at room temperature, followed by the addition of the support (47.5 g). The resulting suspension was pumped at $10 \mathrm{~cm}^{3} \mathrm{~min}^{-1}$ into the twofluid nozzle (1.4 mm diameter), using an air flow of $0.5 \mathrm{~m}^{3} \mathrm{~h}^{-1}$ to form the spray. The inlet temperature was set at $493 \mathrm{~K}$, the aspiration rate at $35 \mathrm{~m}^{3} \mathrm{~h}^{-1}$ and the outlet temperature at $353 \mathrm{~K}$. The dried particles were separated using a cyclone. 
Tin zeolites. Z940 was used as received for post-synthetic incorporation of tin. ${ }^{19}$ The zeolite $(3.3 \mathrm{~g})$ was added to an aqueous solution of $\mathrm{NaOH}\left(0.3 \mathrm{M}, 100 \mathrm{~cm}^{3}\right)$ and $\mathrm{SnSO}_{4}(0.04 \mathrm{M})$ and the mixture was hold at $338 \mathrm{~K}$ for $30 \mathrm{~min}$ in an Easymax $^{\mathrm{TM}} 102$ reactor system (Mettler Toledo). Thereafter, the treatment was quenched using $2 \mathrm{dm}^{3}$ of deionised water and the suspended material was filtered and washed until neutral $\mathrm{pH}$ of the filtrate was achieved. The solid obtained was ion exchanged in aqueous $\mathrm{NH}_{4} \mathrm{NO}_{3}\left(0.1 \mathrm{M}, 6 \mathrm{~h}, 298 \mathrm{~K}, 100 \mathrm{~cm}^{3}\right.$ per gram of dried zeolite, 3 times), dried (338 K, $16 \mathrm{~h}$ ) and calcined. This material was labelled as Sn-MFI. Another catalyst coded as [Sn]BEA was prepared by hydrothermal synthesis following a reported procedure. ${ }^{20}$ Briefly, tetraethyl orthosilicate (Sigma-Aldrich, 99.9\%, $30 \mathrm{~g}$ ) and tetraethyl ammonium hydroxide (Sigma-Aldrich, $35 \mathrm{wt} \%, 33 \mathrm{~g}$ ) were mixed for $90 \mathrm{~min}$. A solution of $\mathrm{SnCl}_{4} \cdot 5 \mathrm{H}_{2} \mathrm{O}$ in water $\left(0.45 \mathrm{~g}\right.$ in $\left.2.75 \mathrm{~cm}^{3}\right)$ was added and the stirring was continued until complete evaporation of the ethanol formed upon hydrolysis. Then, HF (SigmaAldrich, $48 \mathrm{wt} \%$ in water, $3.2 \mathrm{~g}$ ) was added to the clear solution under stirring, resulting in the formation of a thick gel. Thereafter, commercial zeolite beta (Tosoh Corporation, HSZ-980HOA, bulk $\mathrm{Si} / \mathrm{Al}=220,0.36 \mathrm{~g})$ suspended in water $\left(0.36 \mathrm{~g}\right.$ in $\left.2.75 \mathrm{~cm}^{3}\right)$ was added to act as a nucleation seed and the gel was transferred into a $100 \mathrm{~cm}^{3}$ Teflon-lined autoclave and heated at $413 \mathrm{~K}$ for 11 days. The [Sn]BEA solid obtained was subjected to the same filtration, calcination and ion exchange procedures as described above.

\section{Catalyst characterisation}

The metal content in the samples was determined by X-ray fluorescence (XRF) spectroscopy using an EDAX Orbis Micro$\mathrm{XRF}$ analyser equipped with a Rh source operated at a voltage of $35 \mathrm{kV}$ and a current of $500 \mu \mathrm{A}$. Powder X-ray diffraction (XRD) was performed using a PANalytical X'Pert PRO-MPD diffractometer with Ni-filtered $\mathrm{Cu} \mathrm{K} \alpha$ radiation $(\lambda=$ $0.1541 \mathrm{~nm})$, acquiring data in the $5-70^{\circ} 2 \theta$ range with a step size of $0.05^{\circ}$ and a counting time of $8 \mathrm{~s}$ per step. $\mathrm{N}_{2}$ sorption was conducted at $77 \mathrm{~K}$ using a Micromeritics Tristar analyser. Prior to the measurements, the samples were evacuated at $573 \mathrm{~K}$ and $10^{-4}$ bar for $3 \mathrm{~h}$. Fourier transform infrared (FTIR) spectroscopy of adsorbed pyridine (Sigma-Aldrich, >99\%) was carried out using a Bruker IFS66 spectrometer equipped with a liquid- $\mathrm{N}_{2}$ cooled mercury cadmium telluride (MCT) detector. Sample wafers (ca. $\left.1 \mathrm{~cm}^{2}, 0.02 \mathrm{~g}\right)$ were evacuated $\left(10^{-6} \mathrm{bar}\right)$ for $4 \mathrm{~h}$ at $693 \mathrm{~K}$, prior to adsorption at room temperature. Gaseous and weakly adsorbed molecules were subsequently removed by evacuation at $373 \mathrm{~K}$ (for selected samples) and at $473 \mathrm{~K}$ for $30 \mathrm{~min}$. Spectra were recorded in the range of $650-4000 \mathrm{~cm}^{-1}$ with a resolution of $4 \mathrm{~cm}^{-1}$ and co-addition of 32 scans. The concentration of Brønsted- and Lewis-acid sites was calculated from the area of the pyridine bands at 1545 and $1454 \mathrm{~cm}^{-1}$, respectively, using their corresponding extinction

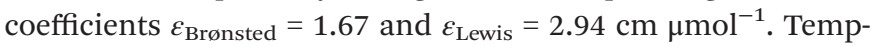
erature-programmed reduction with hydrogen $\left(\mathrm{H}_{2}\right.$-TPR) was performed using a Micromeritics Autochem II 2920 unit connected to a MKS Cirrus 2 quadrupole mass spectrometer. The samples $(0.1 \mathrm{~g})$ were pre-treated in He flow $\left(20 \mathrm{~cm}^{3} \mathrm{~min}^{-1}\right)$ at
$423 \mathrm{~K}$ for $1 \mathrm{~h}$, cooled to $308 \mathrm{~K}$ and finally heated up to $1273 \mathrm{~K}$ $\left(10 \mathrm{~K} \mathrm{~min}^{-1}\right.$ ) while monitoring the consumption of $\mathrm{H}_{2}$ and the formation of $\mathrm{H}_{2} \mathrm{O}$. Quantification was achieved by integration of the area of the reduction peaks, using the results obtained in the $\mathrm{H}_{2}$-TPR of known amounts of $\mathrm{CuO}$ for calibration. Thermogravimetric analysis (TGA) of the used catalysts was conducted using a Mettler Toledo TGA/DSC1 instrument. The samples $(0.015 \mathrm{~g})$ were heated in the range of $323-1023 \mathrm{~K}$ $\left(10 \mathrm{~K} \mathrm{~min}^{-1}\right)$ under an air flow $\left(40 \mathrm{~cm}^{3} \mathrm{~min}^{-1}\right)$. The weight loss between 523-1023 $\mathrm{K}$ was ascribed to the removal of carbonaceous deposits. X-ray photoelectron spectroscopy (XPS) was carried out under UHV $\left(10^{-8}\right.$ mbar $)$ using a VG Thermo Escalab 220i-XL spectrometer equipped with a high-intensity twin anode ( $\mathrm{Al} \mathrm{K} \alpha$ radiation). In the case of the used $\mathrm{Ag} / \mathrm{Al}_{2} \mathrm{O}_{3}-\mathrm{a}$ sample, the measurement was repeated after sputtering with $4 \mathrm{kV} \mathrm{Ar}^{+}$ions rastered over a $2 \times 2 \mathrm{~mm}$ area. The spectra were charge-corrected with respect to the $\mathrm{Al} 2 \mathrm{p}$ signal at $74.0 \mathrm{eV}$. TEM images were acquired using an FEI Talos instrument operated at $200 \mathrm{kV}$. Powdered samples were deposited on Mo-grids as such.

\section{Catalyst testing}

Gas-phase conversion of GLY to PAl. The oxidehydration of GLY to PAl was studied at ambient pressure in a continuousflow fixed-bed reactor (Scheme 2a) comprising: (i) mass flow controllers for feeding $\mathrm{N}_{2}$ (PanGas, 99.999\%), $\mathrm{H}_{2}$ (PanGas, 99.999\%) and $\mathrm{O}_{2}$ (PanGas, 99.995\%), (ii) a syringe pump for feeding an aqueous GLY (Sigma-Aldrich, 99\%) solution, (iii) a tubular quartz micro-reactor (i.d. $=6 \mathrm{~mm}$ ) heated in an oven, (iv) a liquid-gas separator immersed in an ice bath and (v) a bag for the collection of gaseous samples. The supported metal catalysts $(0.1 \mathrm{~g}$, particle size $=0.2-0.4 \mathrm{~mm})$ were loaded into the reactor, which was then filled with 2-mm glass spheres in order to facilitate the evaporation of the liquid feed. The system was heated at the reaction temperature $(623 \mathrm{~K})$ in an $\mathrm{N}_{2}$ flow (100 $\mathrm{cm}^{3} \mathrm{~min}^{-1}$ ) and allowed to equilibrate for $30 \mathrm{~min}$. Thereafter, the gas composition was changed to $20 \mathrm{vol} \%$ $\mathrm{H}_{2} / \mathrm{N}_{2}\left(100 \mathrm{~cm}^{3} \mathrm{~min}^{-1}\right)$ for $60 \mathrm{~min}$ to reduce the metal. Finally, $\mathrm{O}_{2} / \mathrm{N}_{2}$ (typically $1.5 \mathrm{vol} \%, 100 \mathrm{~cm}^{3} \mathrm{~min}^{-1}$ ) was admitted along with a $10 \mathrm{wt} \%$ aqueous GLY solution $\left(0.1 \mathrm{~cm}^{3} \mathrm{~min}^{-1}\right)$. Liquid samples were periodically collected at the reactor outlet and analysed by high-performance liquid chromatography (HPLC) using a Merk LaChrome system equipped with a HPX-87H column kept at $308 \mathrm{~K}$ and refraction index and UV-Vis detectors. A $0.005 \mathrm{M}$ aqueous $\mathrm{H}_{2} \mathrm{SO}_{4}$ solution flowing at $0.600 \mathrm{~cm}^{3} \mathrm{~min}^{-1}$ was used as the eluent. Calibration curves were measured in the 0.1-10 wt\% range using GLY (SigmaAldrich, 99\%), Ac (Alfa Aesar, 95\%), PAl (Acros Organics, 40 wt\% aqueous solution), PAc (ABCR, 98\%), Acr (Fluka, >95\%), AAc (Acros Organics, 99.5\%), DHA (Merck, >98\%), GAl (SigmaAldrich, $>90 \%$ ) and GAc (Acros Organics, >99.7\%). CO and $\mathrm{CO}_{2}$ in the gas samples were analysed by gas chromatography using a HP5890 unit equipped with a gas-sampling valve, a Restek-Shin Carbon ST80/100 column and a thermal conductivity detector. Helium was used as the carrier gas. The concentrations of the carbon oxides were determined from their absolute peak areas using calibration curves measured in the 
(a)

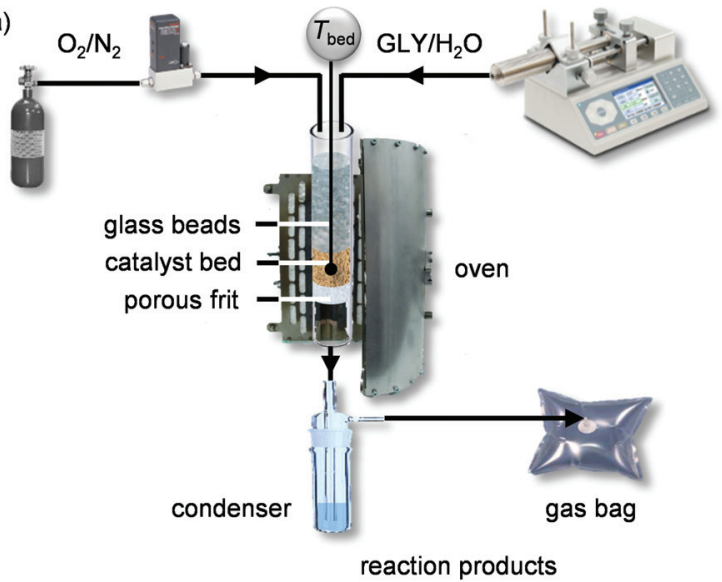

(b)

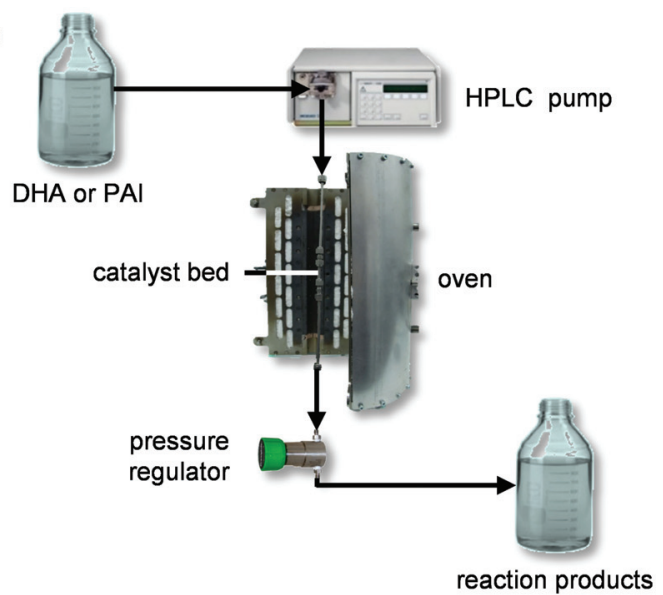

Scheme 2 Reactor setups used for (a) the continuous gas-phase conversion of GLY into PAl and (b) the continuous liquid-phase conversion of DHA and PAl into LA.

0-10 wt\% range. The conversion of GLY $\left(X_{\mathrm{GLY}}\right)$ and selectivity to the product $i\left(S_{i}\right)$ were calculated as:

$$
\begin{aligned}
& X_{\mathrm{GLY}}=1-\left(n_{\mathrm{GLY}, \text { out }} / n_{\mathrm{GLY}, \text { in }}\right) \\
& S_{i}=n_{i, \text { out }} /\left(n_{\mathrm{GLY}, \text { in }}-n_{\mathrm{GLY}, \text { out }}\right)
\end{aligned}
$$

where $n$ refers to the moles of GLY or compound $i$ and in/out to the reactor inlet/outlet. The carbon balance was obtained as the ratio between the moles of carbon in the liquid and gaseous products and the moles of carbon fed. The experimental error, determined by three repetitions of the same catalytic run, was within 5\%. No GLY conversion was observed in blank tests conducted with only quartz particles and the glass beads loaded into the reactor.

Liquid-phase conversion of DHA and PAl to LA or ML. Batch catalytic experiments for the conversion of DHA or PAl into LA were carried out under autogenous pressure in $15 \mathrm{~cm}^{3}$ thickwalled glass vials (Ace, pressure tubes, front seal) dipped in an oil bath heated at 333-423 $\mathrm{K}$. The vials were loaded with $\mathrm{ca}$. $10 \mathrm{~cm}^{3}$ of a $0.33 \mathrm{M}$ aqueous DHA solution (Merk, 98\%) or PAl (Acros Organics, $40 \mathrm{wt} \%$ in water). Then, Sn-MFI (ca. $0.01 \mathrm{~g}$ ) was added to achieve a substrate/tin molar ratio of 1000 . The mixture was allowed to react under vigorous stirring for 15 min. Thereafter, the reactions were quenched using an ice bath and the catalysts were removed by means of a Chromafil Xtra $0.25 \mu \mathrm{m}$ syringe filter. The continuous conversion of DHA and PAl into LA or ML was studied in a homemade continuous-flow reactor setup (Scheme 2b) comprising (i) an HPLC pump (Gilson-306), (ii) a stainless-steel tubular reactor with a pre-column (Swagelok SS-T4-S-035, i.d. = $4.6 \mathrm{~mm}$ ), both heated in a tubular oven, (iii) a backpressure regulator (Swagelok, LH2981001) and (iv) an automatic sampler. The reactor was loaded with the Sn-containing zeolite catalysts $(0.10 \mathrm{~g})$ diluted with quartz ( $1 \mathrm{~g}$, particle size $=0.25-0.36 \mathrm{~mm}$ ) and a liquid feed $\left(0.2 \mathrm{~cm}^{3} \mathrm{~min}^{-1}\right)$ was admitted which contained the substrate $(0.33 \mathrm{M})$ dissolved in water or methanol. Thereafter, the system was pressurised to 20 bar and heated to $383 \mathrm{~K}$ or $343 \mathrm{~K}$ in the case of the conversion of DHA or PAl, respectively. Samples were periodically collected at the outlet of the reactor and analysed by HPLC using the same instrument and method as described for the analysis of the condensate obtained from the conversion of GLY. An additional calibration curve was measured in the $0.1-10 \mathrm{wt} \%$ range for L-lactic acid (ABCR, 98\%). For the reactions performed in methanol, the amount of ML produced was determined using a gas chromatograph (HP 6890) equipped with an HP-5 capillary column and a flame ionisation detector. Quantification was accomplished by integration of its peak using 2,2,4-trimethylpentane (Fluka, 99.5\%) as the internal standard. Conversion and selectivity data were calculated as mentioned above.

\section{Computational details}

Simulations were conducted using the Vienna Ab-initio Simulation Package (VASP) ${ }^{21}$ and the RPBE functional. ${ }^{22}$ Core electrons were described by projector augmented wave (PAW) pseudopotentials, ${ }^{23}$ while valence electrons by a kinetic energy cutoff of $450 \mathrm{eV}$. Although its true structure has been debated for long, ${ }^{24}$ experimental observations herein gathered indicate that silver forms a partially oxidised ultrathin film in $\mathrm{O}_{2}$-rich environments that is commensurate with the $\mathrm{p}(4 \times 4) \operatorname{Ag}(111)$ unit cell. Therefore, three different models were used to describe the silver catalyst to account for poor, medium and rich oxygen conditions, respectively (Fig. 1). Metallic silver, which dominates at low $\mathrm{O}_{2} / \mathrm{GLY}$ ratios, was represented by
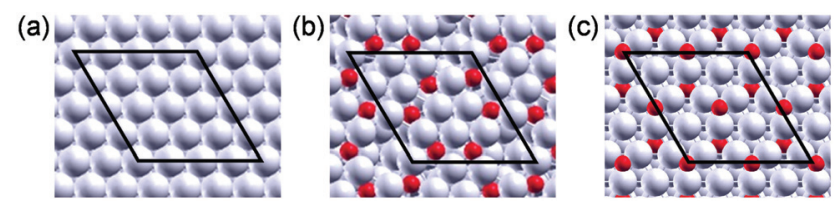

Fig. 1 Representation of the three (111) surfaces used as the models for (a) metallic $\mathrm{Ag}$, (b) the partially oxidised metal $\mathrm{AgO}_{x} / \mathrm{Ag}$ and (c) the bulk oxide $\mathrm{Ag}_{2} \mathrm{O}$. 
4 layers of a clean $4 \times 4 \mathrm{Ag}(111)$ surface. For intermediate $\mathrm{O}_{2} /$ GLY ratios $(\sim 0.5)$, the $\mathrm{p}(4 \times 4)$ model reported elsewhere ${ }^{24 b}$ was used. This can be generated from metallic $\mathrm{Ag}(111)$ by removing 4 metal atoms and adding 6 oxygen atoms to the topmost layer. The lattice parameter of the bulk metal was $4.22 \AA$, in good agreement with the experimental value of $4.09 \AA^{25}$ Thus, both metallic and oxygen-covered silver surfaces have a length of $11.94 \AA$ A. Finally, for high $\mathrm{O}_{2} / \mathrm{GLY}$ ratios, the $\mathrm{p}(2 \times 2) \mathrm{Ag}_{2} \mathrm{O}(111)$ surface was used. Here, the on-surface distance between the cells is $13.92 \AA$, very similar to the one of $\mathrm{Ag}(111)$. For completeness, a model comprising a silver oxide layer epitaxially-grown on metallic silver, $\mathrm{Ag}_{2} \mathrm{O} / \mathrm{Ag}(111)$, was also investigated. Details to this model are provided in the ESI. $\uparrow$ For all of the surfaces, the two topmost layers were relaxed while keeping the two bottom ones fixed to the bulk distances. The density of states for the clean surfaces is shown in Fig. S1. $\dagger$

The Brillouin zone was sampled by a $3 \times 3 \times 1$ Г-centred $k$-points mesh generated through the Monkhorst-Pack method. ${ }^{26}$ To avoid spurious interactions between the periodic images, a vacuum region between the slabs of $15 \AA$ and dipole correction along $z$ were included. ${ }^{27}$ To find the transition states, the climbing image nudged elastic band (CI-NEB) method was employed. ${ }^{28}$ The optimisation thresholds of $10^{-5}$ and $10^{-3} \mathrm{eV}$ were applied for electronic and ionic relaxations, respectively. The assessment of the minima and transition states was performed by diagonalising the numerical Hessian matrix obtained by $\pm 0.02 \AA$ displacements. In the calculation of frequencies, the surface atoms were kept frozen, except for the oxygen atoms on $\mathrm{AgO}_{x} / \mathrm{Ag}$ or $\mathrm{Ag}_{2} \mathrm{O}$ that were part of the reaction. All of the DFT energies reported along the manuscript include zero-point energies.

\section{Results and discussion}

\section{Catalytic oxidehydration of GLY to PAl}

Evaluation of alumina-supported metal catalysts. A series of alumina-supported metal catalysts were prepared to assess the role of the metal in the conversion of GLY into PAl. The metals comprised V, Ni, Fe, Sn, $\mathrm{Cu}, \mathrm{Ru}, \mathrm{Ag}, \mathrm{Pd}, \mathrm{Pt}$ and $\mathrm{Au}$ and were selected among noble and non-noble transition metals based on their reported catalytic activity in the dehydrogenation of alcohols. They are characterised by different redox potentials, spanning from -1.13 to $1.68 \mathrm{~V}$, relatively to the semi-reactions reported in Table $1 .^{25}$ The metal content in the final materials was similar and was comprised between 4.4 and $5.1 \mathrm{wt} \%$ in all cases except for $\mathrm{Ni}$ and $\mathrm{Sn}$. For these, the loading was limited to 3.1 and $1.9 \mathrm{wt} \%$, respectively, due to the poor water solubility of the precursors. The choice of the alumina carrier was based on literature reports indicating that the reaction proceeds through the dehydration of GLY to Ac, followed by its dehydrogenation, and that the first reaction is catalysed by Lewis-acid sites. ${ }^{3}$ Indeed, testing of the bare support yielded a GLY conversion of $53 \%$ with high Ac selectivity (85\%, Table $\mathrm{S} 1 \dagger)$. The most prominent by-product was Acr. The impregnation of the support with the metal precursors led to only minor modification in the surface area and did not significantly alter its Lewis acidity. In contrast, its mild Brønsted acidity (Table 1) generally decreased, likely due to the replacement of protons at ion-exchange positions with the metal cations, except for the $\mathrm{Cu}^{-}, \mathrm{Ru}-$ and $\mathrm{Pd}-$ based catalysts. For these, a slight increase was noticed, which could be associated with the higher electronegativity of the metals and thus with the stronger acidic nature of $\mathrm{H}$ atoms of hydroxyl groups.

Fig. 2a shows the catalytic data collected upon testing of the catalysts in the gas-phase oxidehydration of GLY at $623 \mathrm{~K}$. With the exception of the Pt- and Au-based samples, all of the materials attained a high GLY conversion level. This suggests that a certain degree of oxidation of the metal is advantageous, which cannot be achieved with the most noble metals. The product distribution, evidencing a low Ac selectivity at high PAl yields and vice versa, is in line with the two-step reaction path proposed in Scheme $1 \mathrm{~b}$. Only minor amounts of DHA $(<1 \%)$, Gal $(<1 \%)$ and GAc $(<2 \%)$ were detected (Table S1 $\dagger$ ), indicating that the direct dehydrogenation of the hydroxyl groups of GLY is hindered under these conditions. Indeed, we have recently reported the oxidation of GLY to DHA to happen at much higher $\mathrm{O}_{2} / \mathrm{GLY}$ ratios over steamed iron-containing silicalite featuring negligible acidity. ${ }^{8 b}$ The competitive dehydration reaction leading to Acr, which can be further converted into AAc under oxidising conditions, was relevant only in the case of Sn-, $\mathrm{Cu}$ - and $\mathrm{Ru}$-containing materials. This was

Table 1 Characterisation data for the alumina-supported metal catalysts

\begin{tabular}{|c|c|c|c|c|c|c|c|}
\hline Catalyst & Metal content ${ }^{a}(\mathrm{wt} \%)$ & $S_{\mathrm{BET}}^{b}\left(\mathrm{~m}^{2} \mathrm{~g}^{-1}\right)$ & $V_{\text {pore }}{ }^{c}\left(\mathrm{~cm}^{3} \mathrm{~g}^{-1}\right)$ & $C_{\text {Lewis }}{ }^{d}\left(\mu \mathrm{mol} \mathrm{g}^{-1}\right)$ & $C_{\text {Brønsted }}{ }^{d}\left(\mu \mathrm{mol} \mathrm{g}{ }^{-1}\right)$ & $E_{\mathrm{h}}^{e}(\mathrm{~V})$ & Semi-reaction \\
\hline $\mathrm{V} / \mathrm{Al}_{2} \mathrm{O}_{3}-\mathrm{a}$ & 4.9 & 74 & 0.39 & 65 & 8 & -1.13 & $\mathrm{~V}^{2+}+2 \mathrm{e}^{-} \rightarrow \mathrm{V}$ \\
\hline $\mathrm{Ni} / \mathrm{Al}_{2} \mathrm{O}_{3}-\mathrm{a}$ & 3.1 & 76 & 0.45 & 61 & 7 & -0.72 & $\mathrm{Ni}^{2+}+2 \mathrm{e}^{-} \rightarrow \mathrm{Ni}$ \\
\hline $\mathrm{Sn} / \mathrm{Al}_{2} \mathrm{O}_{3}-\mathrm{a}$ & 1.9 & 78 & 0.44 & 80 & 4 & -0.14 & $\mathrm{Sn}^{2+}+2 \mathrm{e}^{-} \rightarrow \mathrm{Sn}$ \\
\hline $\mathrm{Cu} / \mathrm{Al}_{2} \mathrm{O}_{3}-\mathrm{a}$ & 4.5 & 81 & 0.38 & 68 & 18 & 0.34 & $\mathrm{Cu}^{2+}+2 \mathrm{e}^{-} \rightarrow \mathrm{Cu}$ \\
\hline $\mathrm{Ru} / \mathrm{Al}_{2} \mathrm{O}_{3}-\mathrm{a}$ & 5.1 & 72 & 0.40 & 76 & 16 & 0.70 & $\mathrm{Ru}^{4+}+4 \mathrm{e}^{-} \rightarrow \mathrm{Ru}$ \\
\hline $\mathrm{Ag} / \mathrm{Al}_{2} \mathrm{O}_{3}-\mathrm{a}$ & 4.8 & 74 & 0.45 & 72 & 8 & 0.80 & $\mathrm{Ag}^{+}+\mathrm{e}^{-} \rightarrow \mathrm{Ag}$ \\
\hline $\mathrm{Au} / \mathrm{Al}_{2} \mathrm{O}_{3}-\mathrm{a}$ & 4.4 & 80 & 0.46 & 69 & 4 & 1.83 & $\mathrm{Au}^{+}+\mathrm{e}^{-} \rightarrow \mathrm{Au}$ \\
\hline
\end{tabular}

${ }^{a}$ XRF spectroscopy. ${ }^{b}$ BET method. ${ }^{c}$ Volume adsorbed at $p / p_{0}=0.99 .{ }^{d}$ FTIR spectroscopy of adsorbed pyridine, after desorption at $473 \mathrm{~K} .{ }^{e}$ Redox potential of the semi-reaction reported in the column on the right. ${ }^{28}$ 

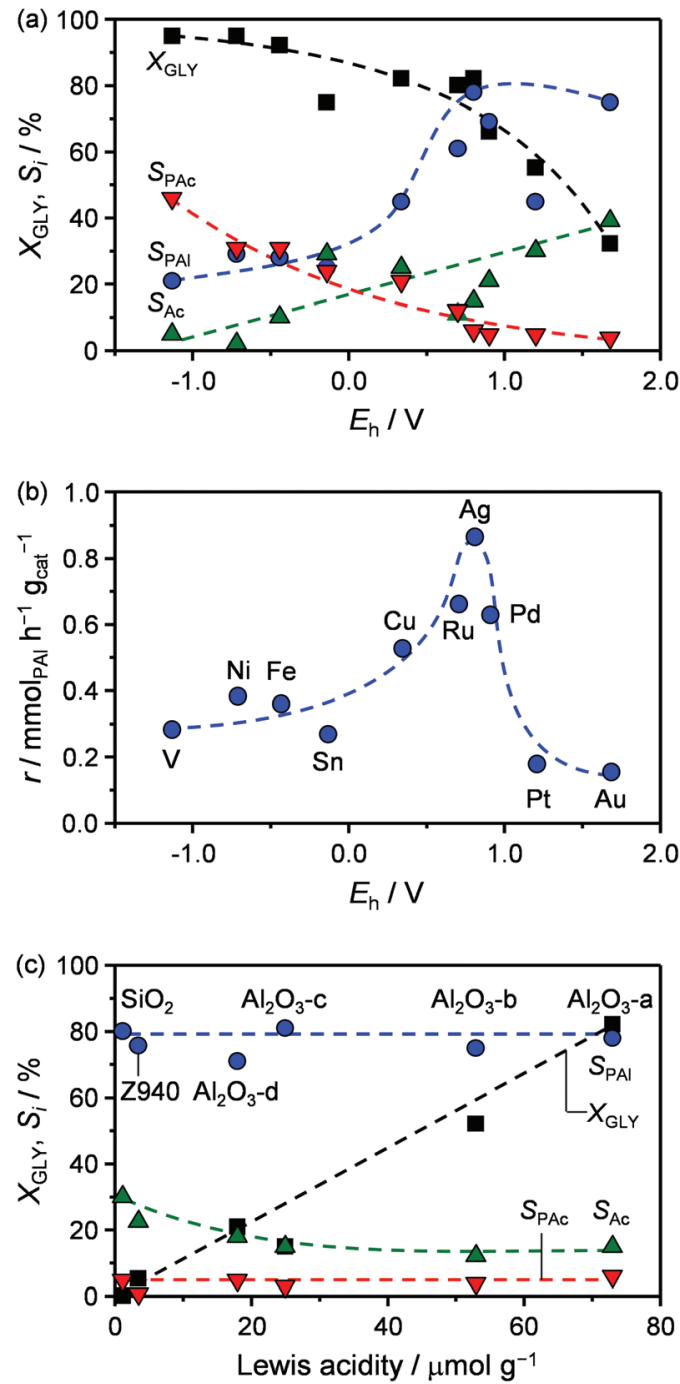

Fig. 2 (a) GLY conversion and selectivities to Ac, PAl and PAC as a function of the metal reduction potential for alumina-supported catalysts and (b) the corresponding PAl formation rate. (c) Reaction performance vs. the Lewis-acid sites concentration for alumina-, $\mathrm{Z940-}$ and $\mathrm{SiO}_{2}-$ supported silver catalysts. Reaction conditions: $T=623 \mathrm{~K}, P=1 \mathrm{bar}$, $C_{\mathrm{GLY}}=10 \mathrm{wt} \%$, LHSV $=6 \mathrm{~h}^{-1}$ and $\mathrm{O}_{2} / \mathrm{GLY}=0.5$. explained by their comparatively high concentration of Brønsted acid sites, which are well-known active centres for the selective formation of this molecule from GLY. Pt- and Pdcontaining solids, which evidenced moderate acidity upon pyridine adsorption did not show this behaviour likely because of their fully reduced status under the reaction conditions and the consequent absence of hydroxyl groups on their surface. Overall, the selectivity to the dehydration product (Ac) was higher for those materials containing a more noble metal. Assuming that GLY dehydration mostly takes place on the support and the Ac dehydrogenation is catalysed by the metal, this implies a lower activity of these metals in the dehydrogenation step. On the other hand, over-oxidation of PAl to PAc was favoured on non-noble metals. Furthermore, up to $8 \%$ of the GLY fed was converted into $\mathrm{CO}$ and $\mathrm{CO}_{2}$. Overall, the Agbased catalyst was superior to the other systems due to a good balance between activity and selectivity to PAl. This is visualised in Fig. 2b, which highlights a maximum for the PAl yield (80\%) over this material. Notably, this yield matches the state-of-theart data claimed in a patent over another Ag-based solid. ${ }^{15}$ Accordingly, this catalyst was chosen for further studies.

Support selection for silver catalysts. A series of silver catalysts was prepared using supports with distinct acid-base properties (Table $\mathrm{S} 2 \uparrow$ ), to explore whether the catalyst activity could be further enhanced by optimising the first step. The carriers comprised 3 additional aluminas, leading to solids featuring different Lewis acidity, 2 zeolites with MFI framework topology and a Si/Al ratio of $c a .40$ or 940 as well as amorphous silica and silica-alumina, generating catalysts with very diverse Brønsted and Lewis acidity (Table 2). The specific surface area of the carriers was in line with that generally reported for these materials and was not substantially altered by the deposition of the silver phase, suggesting a good metal dispersion. An increased Lewis-acidic character was shown to be beneficial to raise the conversion of the substrate while keeping a high selectivity (Fig. 2c). Indeed, for all the aluminasupported samples a linear conversion- $v s$.-Lewis acidity trend was observed. The strength of the Lewis-acid sites appeared to play no significant role, since it varied significantly among materials displaying a similar selectivity (Table 2). Brønstedacid sites proved extremely detrimental for the selectivity of

Table 2 Characterisation data for the Ag-based catalysts

\begin{tabular}{|c|c|c|c|c|c|c|c|}
\hline Support & $\begin{array}{l}\mathrm{Ag}^{a} \\
\text { (wt\%) }\end{array}$ & $\begin{array}{l}S_{\mathrm{BET}} b \\
\left(\mathrm{~m}^{2} \mathrm{~g}^{-1}\right)\end{array}$ & $\begin{array}{l}V_{\text {pore }}{ }^{c} \\
\left(\mathrm{~cm}^{3} \mathrm{~g}^{-1}\right)\end{array}$ & $\begin{array}{l}C_{\text {Lewis }}{ }^{d} \\
\left(\mu \mathrm{mol} \mathrm{g}{ }^{-1}\right)\end{array}$ & $\begin{array}{l}C_{\text {Brønsted }}^{d} \\
\left(\mu \mathrm{mol} \mathrm{g}^{-1}\right)\end{array}$ & $\begin{array}{l}\text { Lewis sites } \\
\text { strength }^{e}\end{array}$ & $\begin{array}{l}\text { Brønsted sites } \\
\text { strength }^{e}\end{array}$ \\
\hline $\mathrm{Ag} / \mathrm{Al}_{2} \mathrm{O}_{3}-\mathrm{a}$ & 4.8 & 74 & 0.45 & 72 & 8 & 0.91 & 0.45 \\
\hline $\mathrm{Ag} / \mathrm{Al}_{2} \mathrm{O}_{3}-\mathrm{b}$ & 4.8 & 70 & 0.38 & 53 & 2 & 0.86 & 0.52 \\
\hline $\mathrm{Ag} / \mathrm{Al}_{2} \mathrm{O}_{3}-\mathrm{c}$ & 4.9 & 73 & 0.51 & 25 & 0 & 0.60 & - \\
\hline $\mathrm{Ag} / \mathrm{Al}_{2} \mathrm{O}_{3}-\mathrm{d}$ & 4.8 & 76 & 0.56 & 18 & 0 & 0.75 & - \\
\hline $\mathrm{Ag} / \mathrm{SiO}_{2}$ & 4.9 & 121 & 0.35 & 1 & 0 & 1.00 & - \\
\hline Ag/ASA & 5.1 & 80 & 0.61 & 51 & 54 & 0.41 & 0.88 \\
\hline $\mathrm{Ag} / \mathrm{Z} 940$ & 4.7 & 325 & 0.19 & 21 & 0 & 0.80 & - \\
\hline $\mathrm{Ag} / \mathrm{Z} 40$ & 5.0 & 403 & 0.21 & 89 & 151 & 0.57 & 0.79 \\
\hline
\end{tabular}

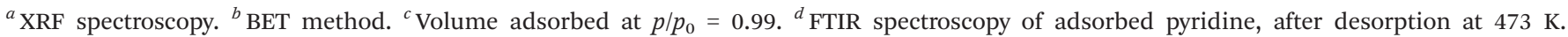
${ }^{e}$ Defined as the ratio between the sites probed by pyridine after desorption at 473 and at $373 \mathrm{~K}$. 
the reaction (Fig. S2 $\dagger$ ). While promoting a high GLY conversion, the strongly Brønsted-acidic Z40 and ASA support limited the formation of the product of interest since they favoured the dehydration of GLY to Acr (Table S1†). Based on these results, a bigger batch of $5 \mathrm{wt} \% \mathrm{Ag} / \mathrm{Al}_{2} \mathrm{O}_{3}$-a was prepared to enable an in-depth characterisation and testing at variable reaction conditions. Spray deposition was used as a synthesis method instead of impregnation due to the higher reproducibility of the properties of the solids obtained by this technique. ${ }^{19}$ The catalyst showed the same catalytic performance as that obtained by impregnation. The XRD pattern of the solid in as-prepared form evidenced, after subtraction of the diffractogram of the bare support, weak reflections specific to Ag(I) oxide (Fig. 3a). After activation of this material by reduction in diluted hydrogen, the diffraction lines of $\mathrm{Ag}_{2} \mathrm{O}$ disappeared and two reflections appeared at 38 and $642 \theta$, which are attributed to metallic silver nanoparticles of about
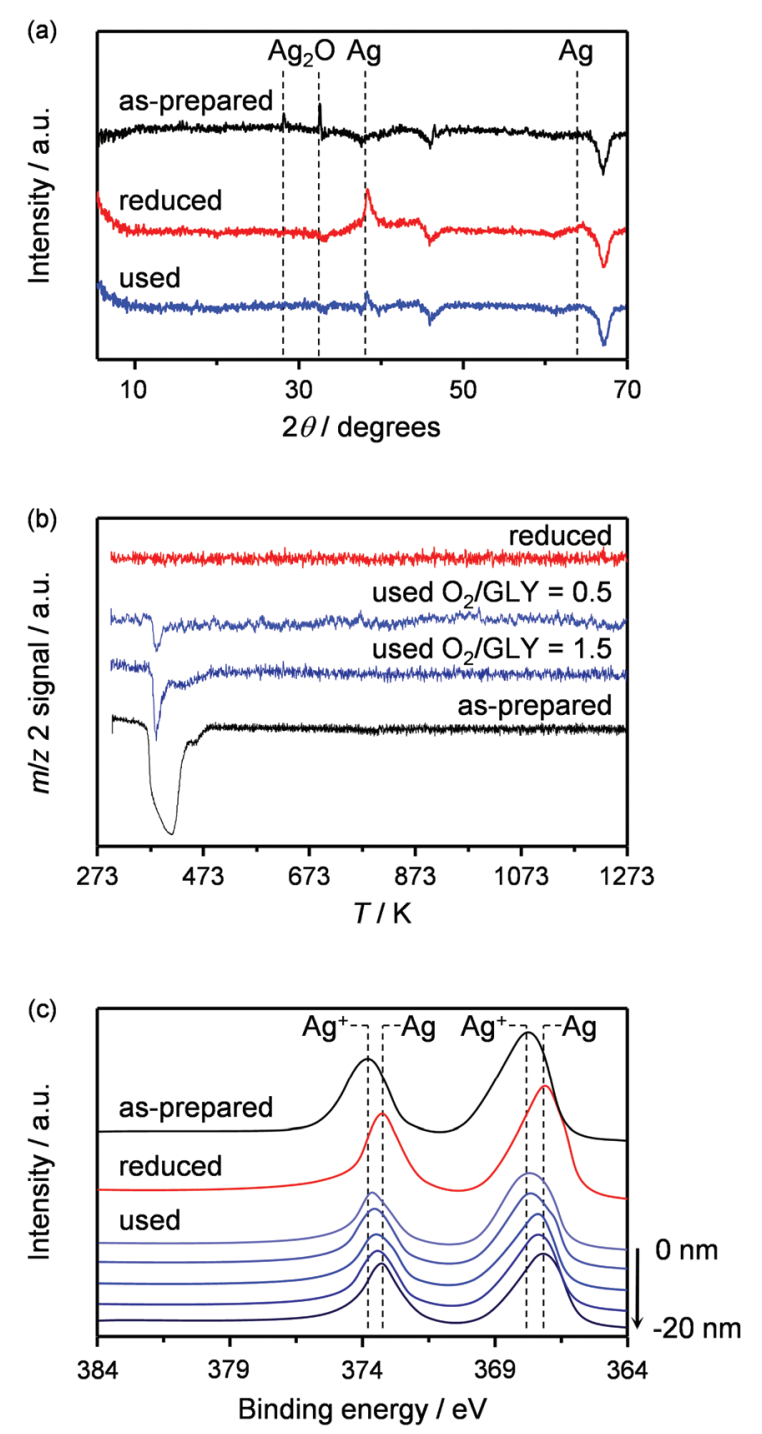

Fig. 3 Characterisation of the as-prepared, activated and used Ag/ $\mathrm{Al}_{2} \mathrm{O}_{3}$-a catalyst by (a) XRD, (b) $\mathrm{H}_{2}-\mathrm{TPR}$ and (c) XPS.
$13 \mathrm{~nm}$ diameter. $\mathrm{H}_{2}$-TPR analysis confirmed the stoichiometry of the silver oxide in the freshly-synthesised sample (Fig. 3b). After activation, negligible hydrogen consumption was measured, indicating the complete reduction to the metallic state. Transmission electron micrographs (Fig. $4 \mathrm{a}$ and b) revealed that the $\mathrm{Ag}_{2} \mathrm{O}$ particles were very small $(c a .5 \mathrm{~nm})$ and that the metallic phase featured larger aggregates (ca. $12 \mathrm{~nm}$ ). The latter evidence is in agreement with the XRD data and indicates that clustering happened upon reduction (Fig. 3a). Finally, the nature of the metal surface was investigated by XPS (Fig. 3c). A signal centred at $368.2 \mathrm{eV}$ was observed for the asprepared sample, which is attributed to the $3 \mathrm{~d}$ transition of $\operatorname{Ag}(\mathrm{I})$ species. ${ }^{29}$ After reduction of the catalyst, the position of the $3 \mathrm{~d}$ signal shifted to $367.2 \mathrm{eV}$, as expected for metallic silver. This difference is also in good agreement with the data calculated by DFT (Table S3†), which predicted that the signal of oxidic silver would appear at a $0.7 \mathrm{eV}$ higher binding energy than that of metallic silver.

Impact of the reaction conditions for $\mathbf{A g} / \mathrm{Al}_{2} \mathbf{O}_{3}-\mathbf{a}$. The dependence of the reaction performance on the temperature and on the $\mathrm{O}_{2}$-GLY ratio was studied in the 573-673 $\mathrm{K}$ and 0-1.5 ranges, respectively, using the $5 \mathrm{wt} \% \mathrm{Ag} / \mathrm{Al}_{2} \mathrm{O}_{3}$-a catalyst prepared by spray deposition. As expected, the conversion increased at higher temperatures (Fig. 5a). The selectivity to PAl was preserved until $623 \mathrm{~K}$. Above this temperature, the over-oxidation to PAc increased. This effect is in line with the fact that the oxidation of the aldehyde also happens homogeneously following a non-catalytic radical pathway, the rate of which strongly depends on temperature. ${ }^{30}$ In the absence of oxygen, Ac was the most prominent product (Fig. 5b) and the Acr yield was comparable to that obtained in a blank run with the bare support. This indicates that the rate of dehydrogenation is negligible if $\mathrm{O}_{2}$ is not supplied. As detailed below, it additionally hints the inactivity of the metal in its reduced state or the necessity of reducing the surface coverage of the hydrogen abstracted from the substrate using an oxidant. The PAl yield steeply increased upon addition of $\mathrm{O}_{2}$ reaching $\mathrm{ca} .80 \%$ at $\mathrm{O}_{2} / \mathrm{GLY}=0.5$, i.e., the stoichiometric ratio. Above this value, it diminished due to the more pronounced over-oxidation.

The stability of the catalyst was tested at the optimal temperature and $\mathrm{O}_{2} / \mathrm{GLY}$ ratio in a $24 \mathrm{~h}$ run (Fig. $5 \mathrm{c}$ ). The PAl yield decreased by only ca. $10 \%$ in this test highlighting the robustness of the material. This minor loss of performance was ascribed to the deposition of carbonaceous species $(4.8 \mathrm{wt} \% \mathrm{C}$ on the used catalyst) and a slight sintering of the silver particles from ca. 12 to $15 \mathrm{~nm}$ (Fig. 4c). It should be noted that a catalyst featuring a distinct Brønsted acidity would undergo rapid deactivation by fouling due to the promoted formation of dehydration and condensation products.

\section{DFT simulations on Ac dehydrogenation to PAl}

Since the catalyst testing evidenced a strong influence of the addition of oxygen on the oxidehydration of GLY, the oxidative conversion of Ac to PAl was investigated in greater detail by DFT. The reaction occurs as described hereon. Firstly, Ac adsorbs on the surface (1), which abstracts an $\mathrm{H}$ atom cleaving 
(a)

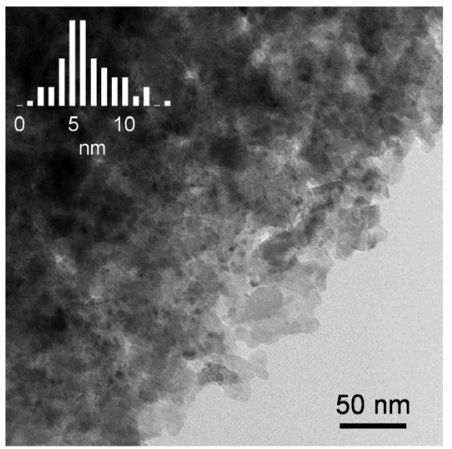

(b)

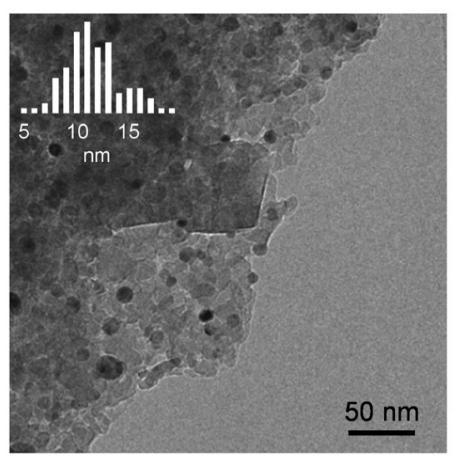

(c)

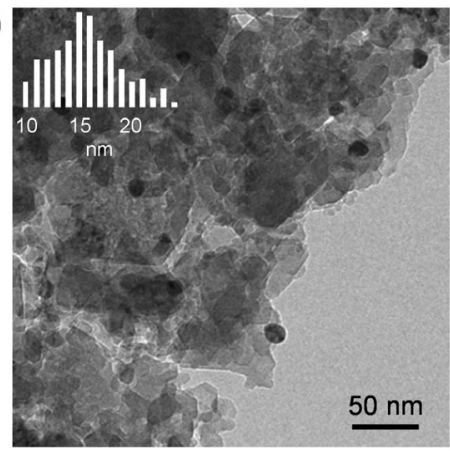

Fig. 4 TEM micrographs for the (a) as-prepared, (b) activated and (c) used $\mathrm{Ag} / \mathrm{Al}_{2} \mathrm{O}_{3}$-a catalyst. The particle size distributions of the $\mathrm{Ag}$-based phase are reported in the insets.
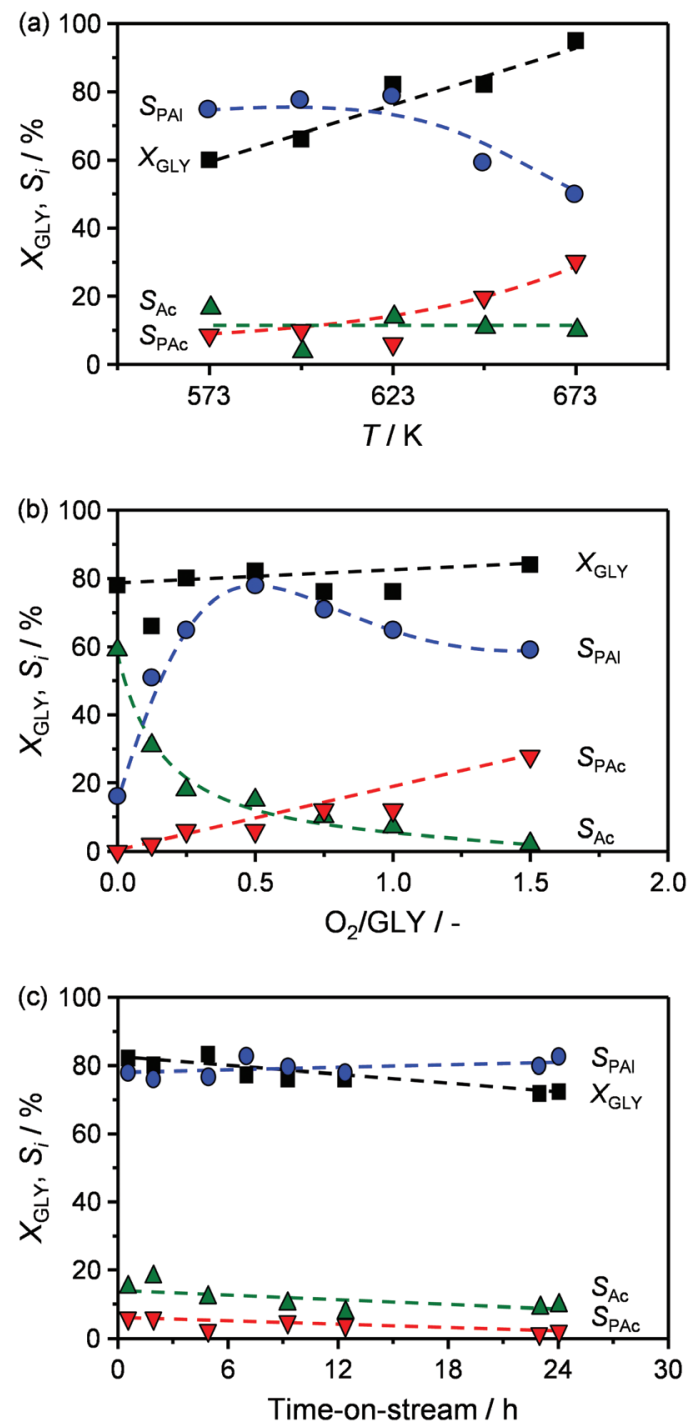

Fig. $5 \mathrm{GLY}$ conversion and product selectivity over $\mathrm{Ag} / \mathrm{Al}_{2} \mathrm{O}_{3}-\mathrm{a}$ as a function of (a) the temperature, (b) the $\mathrm{O}_{2} / \mathrm{GLY}$ ratio and (c) the time on stream. Reaction conditions: $T=623 \mathrm{~K}, P=1 \mathrm{bar}, \mathrm{C}_{\mathrm{GLY}}=10 \mathrm{wt} \%$, LHSV $=6 \mathrm{~h}^{-1}$ and $\mathrm{O}_{2} / \mathrm{GLY}=0.5$. the more labile $\mathrm{O}-\mathrm{H}$ bond (2). ${ }^{31}$ The latter is performed by an $\mathrm{Ag}$ atom on a metallic surface or by an $\mathrm{O}$ atom in the case of $\mathrm{AgO}_{x} / \mathrm{Ag}$ and $\mathrm{Ag}_{2} \mathrm{O}$. Then, the vicinal $\mathrm{C}-\mathrm{H}$ bond is broken (3), forming adsorbed PAl. The reaction proceeds with the desorption of PAl (4). When oxygen is present on the surface, catalyst regeneration occurs through the formation of water by combination of two hydroxyl groups (5). The subsequent desorption of water creates an oxygen vacancy (6), that is healed by the adsorption of an oxygen molecule (7). Albeit comprising multiple steps, the latter is represented as an elementary step for the sake of clarity.

$$
\begin{gathered}
\mathrm{CH}_{3} \mathrm{COCH}_{2} \mathrm{OH}(\mathrm{g})+{ }^{*} \rightarrow \mathrm{CH}_{3} \mathrm{COCH}_{2} \mathrm{OH}^{*} \\
\mathrm{CH}_{3} \mathrm{COCH}_{2} \mathrm{OH}^{*}+{ }^{*} \rightarrow \mathrm{CH}_{3} \mathrm{COCH}_{2} \mathrm{O}^{*}+\mathrm{H}^{*} \\
\mathrm{CH}_{3} \mathrm{COCH}_{2} \mathrm{O}^{*}+{ }^{*} \rightarrow \mathrm{CH}_{3} \mathrm{COCHO}^{*}+\mathrm{H}^{*} \\
\mathrm{CH}_{3} \mathrm{COCHO}^{*} \rightarrow \mathrm{CH}_{3} \mathrm{COCHO}(\mathrm{g})+{ }^{*} \\
\mathrm{OH}^{*}+\mathrm{H}^{*} \rightarrow \mathrm{H}_{2} \mathrm{O}^{*}+{ }^{*} \\
\mathrm{H}_{2} \mathrm{O}^{*} \rightarrow \mathrm{H}_{2} \mathrm{O}(\mathrm{g})+{ }^{*} \\
\frac{1}{2} \mathrm{O}_{2}(\mathrm{~g})+{ }^{*} \rightarrow \mathrm{O}^{*}
\end{gathered}
$$

The energy profiles corresponding to the steps (1)-(4) are shown in Fig. 6, while those relative to steps (5)-(7) are depicted in Fig. S3.† On pure Ag, the adsorption of Ac is endothermic and the barrier for step (2) is higher than on the other two model surfaces, indicating that it shall proceed with very low rates. The second dehydrogenation (3) occurs simultaneously with PAl desorption (4). On $\mathrm{Ag}_{2} \mathrm{O}$, the adsorption of Ac is more exothermic than on the other systems (1), indicating that the bulk oxide traps Ac more effectively. The first dehydrogenation (2) is less energy demanding than for pure Ag and the second dehydrogenation (3) proceeds rapidly and is followed by the exothermic desorption of the desired product PAl. However, water formation (5) is relatively difficult, thus hindering the regeneration of the catalyst. On $\mathrm{AgO}_{x} / \mathrm{Ag}$, the low reaction and activation energies of step (2) suggest that $\mathrm{CH}_{3} \mathrm{COCH}_{2} \mathrm{O}^{*}$ is in equilibrium with adsorbed Ac. Reaction (3) has a low activation energy and is very exothermic. Since step 


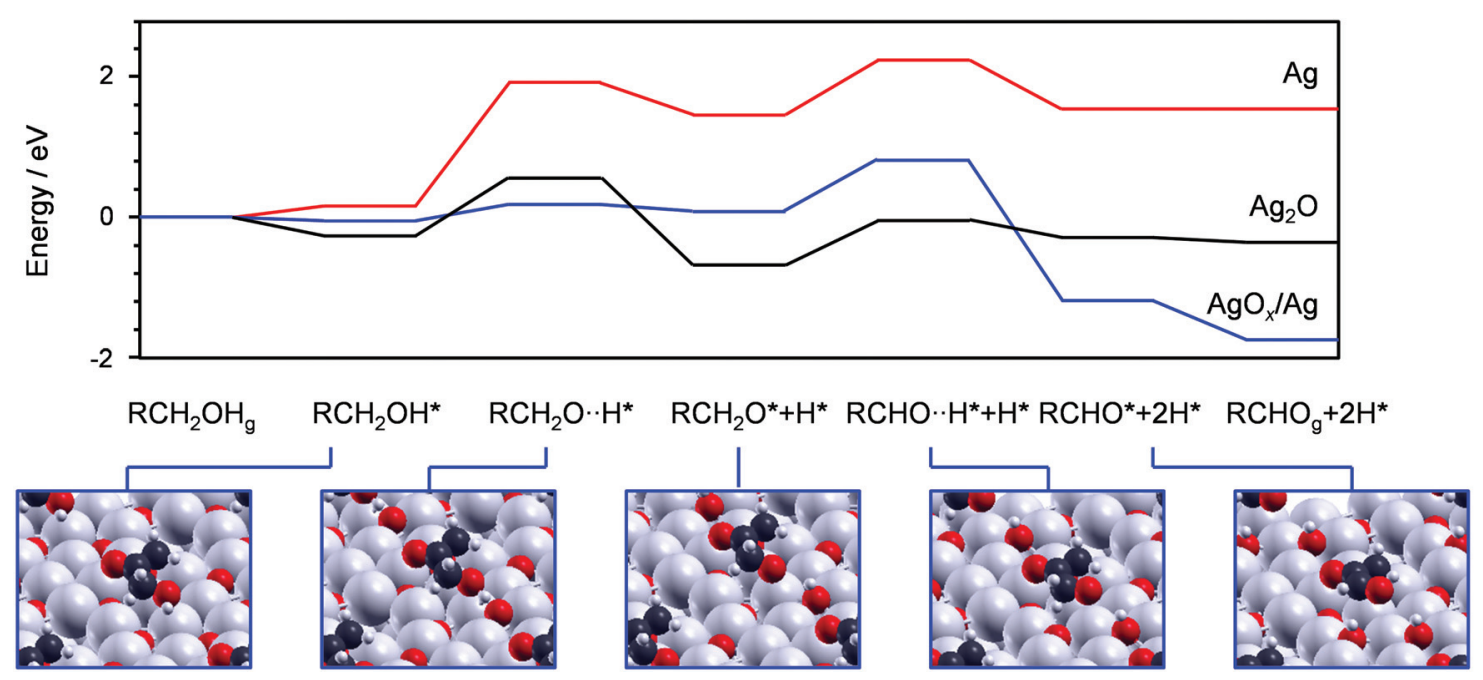

Fig. 6 Energy profiles for the dehydrogenation of Ac to PAl and the corresponding structures calculated over the $\mathrm{AgO}_{x} / \mathrm{Ag}$ surface.

(7) is less energy demanding, the surface will regenerate faster than in the case of bulk $\mathrm{Ag}_{2} \mathrm{O}$. For the oxidic surface and the bulk oxide, PAl desorption is always exothermic, thus preventing the on-surface over-oxidation to PAc. It should be noted that step (2) is an acid-base reaction that could also be catalysed by the support. Spillover of the oxygenate fragment to the metal phase would enable the occurrence of the subsequent steps (3)-(7). However, control experiments with a SiC-supported Ag catalyst excluded the participation of the alumina carrier in the abstraction of the first $\mathrm{H}$ atom (Table $\mathrm{S} 4 \dagger$ ). The results obtained over the $\mathrm{Ag}_{2} \mathrm{O} / \mathrm{Ag}$ surface (Fig. S4 and $\mathrm{S} 5 \dagger$ ) are close to those described for the bulk $\mathrm{Ag}_{2} \mathrm{O}$ system and are discussed in the ESI. $\dagger$

Based on the analysis of the energy diagrams, the high PAl yield found at $\mathrm{O}_{2} / \mathrm{GLY}=0.5$ is explained by its quick elimination from the surface and the easy catalyst regeneration, while the low PAl yields measured for low and high $\mathrm{O}_{2} / \mathrm{GLY}$ ratios are due to a very slow $\mathrm{C}-\mathrm{H}$ stripping and a hindered regeneration of the metal sites, which remain hydroxylated, respectively. These findings hence rationalise the volcanoshape observed in Fig. 5b.

Characterisation data for the $\mathrm{Ag} / \mathrm{Al}_{2} \mathrm{O}_{3}$-a catalyst indicate the surface oxidation of the metal nanoparticles after use under the optimised conditions. This corresponds to the most active surface $\left(\mathrm{AgO}_{x} / \mathrm{Ag}\right)$ analysed for the reaction. Indeed, XRD (Fig. 3a) evidenced a weakening and sharpening of the diffraction peaks attributed to metallic silver, pointing to the formation of bigger particles and of a secondary Ag-based phase, which remained undetected possibly due to the its limited amount and/or high dispersion. $\mathrm{H}_{2}$-TPR analysis (Fig. $3 \mathrm{~b}$ ) showed a reduction peak centred at $c a .523 \mathrm{~K}$, indicating that $c a .13 \%$ of the metal was oxidised to $\mathrm{Ag}(\mathrm{I})$ oxide. The location of this phase was investigated through XPS by measuring spectra after removing a progressively thicker layer of material from the surface by sputtering with $\mathrm{Ar}^{+}$(Fig. 3c). The 3d signal of silver appeared at $368.0 \mathrm{eV}$ in the spectrum of the used untreated sample and stepwise shifted to $367.2 \mathrm{eV}$ in those after irradiation with the ion beam. This finding implies the formation of an oxidised silver shell around a metallic core upon reaction. Since the oxygen-to-silver ratio at the surface was lower than that of $\mathrm{Ag}_{2} \mathrm{O}$, as indicated by the slightly shifted XPS peak, silver might not be fully oxidised to $\mathrm{Ag}(\mathrm{I})$ in this outer layer. The partial oxidation of the $\mathrm{Ag}$ phase upon reaction was confirmed by $\mathrm{H}_{2}$-TPR analysis of another sample, i.e., $\mathrm{Ag} / \mathrm{Al}_{2} \mathrm{O}_{3}$-d (15\%, Fig. S6†). Additionally, characterisation of the $\mathrm{Ag} / \mathrm{Al}_{2} \mathrm{O}_{3}$-a catalyst used at $\mathrm{O}_{2} / \mathrm{GLY}=1.5$ by the same technique revealed a 2.5-times greater extent of oxidation of silver (32\%, Fig. $3 \mathrm{~b}$ ), highlighting the sensitivity of the active phase to the oxygen feed content. The change in oxidation state of the surface silver atoms is analogous to that observed for Ru-based catalysts applied in the transfer hydrogenation of furfural to 2-methylfurane, where the active phase has been reported to include both oxidic and metallic species. The similarity of the two systems is attributed to the similar $E_{\mathrm{h}}$ values of the two metals (Fig. 2b). ${ }^{32}$ It should also be noticed that the partial oxygen pressures and temperatures employed in the reaction herein studied are similar to those commonly applied in ethylene epoxidation. ${ }^{24,33}$ This transformation com-

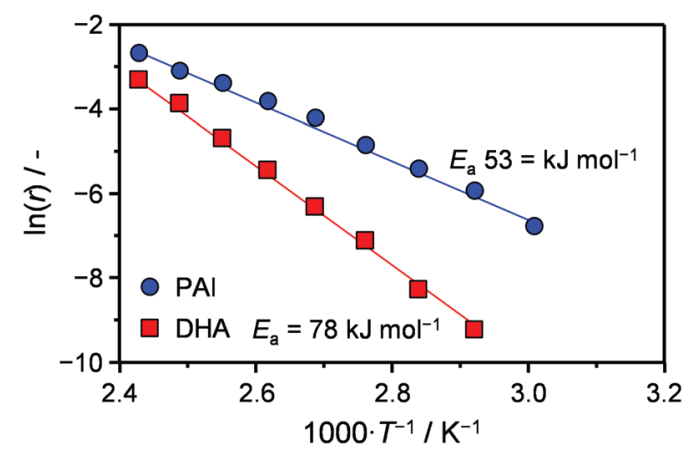

Fig. 7 Rate of LA formation from DHA and PAl over Sn-MFI in water. Reaction conditions: $C_{\mathrm{DHA}}$ PAl $=0.33 \mathrm{M}$ and $\mathrm{DHA}, \mathrm{PAl} / \mathrm{Sn}=1000$. 

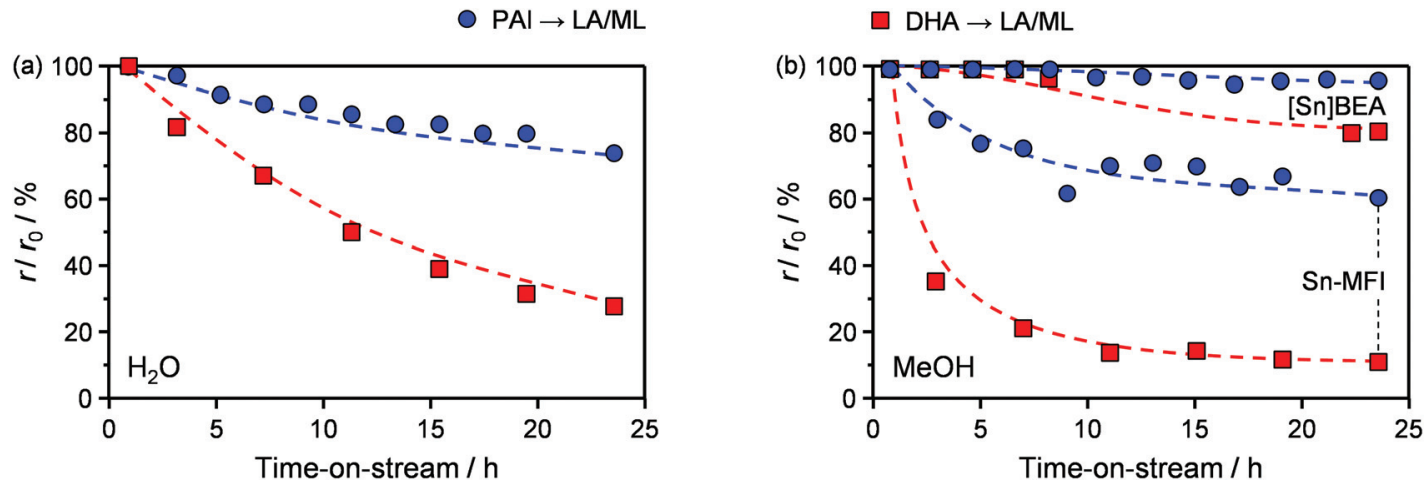

Fig. 8 (a) Percentage of the initial rate of LA formation over Sn-MFI in water and (b) of ML formation over Sn-MFI and [Sn]BEA in methanol. Reaction conditions: $T_{\mathrm{DHA}}=383 \mathrm{~K}, T_{\mathrm{PAl}}=343 \mathrm{~K}, P=20 \mathrm{bar}, C_{\mathrm{DHA}, \mathrm{PAl}}=0.33 \mathrm{M}, \mathrm{LHSV}=120 \mathrm{~h}^{-1}$.

prises the most common application of silver in heterogeneous catalysis and the metal has been found to undergo surface oxidation upon this reaction as well.

\section{Continuous liquid-phase conversion of PAl to LA}

The rate of formation of LA and methyl lactate (ML) from DHA over Sn-containing Lewis-acid zeolites has been reported to be limited by the dehydration of the ketone to PAl (Scheme 1a). ${ }^{12}$ Therefore, the use of the latter as a substrate would enable the same productivity at reduced operation temperatures, thus decreasing the energy demand of the process. Additionally, it is expected that temperature-dependent deactivation processes, including fouling and hydrothermal modifications of the zeolite, would be hindered, lowering the catalyst consumption and the operating costs. To confirm the advantages of the use of PAl as an alternative substrate to DHA for the production of LA and methyl lactate (ML), the state-of-theart [Sn]BEA zeolite as well as a Sn-MFI material prepared by alkaline-assisted stannation were evaluated in the two reactions. The latter catalyst was selected in view of the rapidity and scalability of its preparation which contrast the limited industrial amenability of the synthesis of the former material. ${ }^{19}$ The crystallinity, textural properties and the coordination of the tin sites, probed by diffuse reflectance UV-Vis and acetonitrile-FTIR spectroscopies (Table S5 and Fig. S7†), of the stannosilicates were in good agreement with previous data published for these materials. ${ }^{12}$ At first, Sn-MFI was tested in the conversion of DHA and PAl in batch experiments at different temperatures in order to choose conditions suitable to compare initial turnover frequencies for the two substrates. The results (Fig. 7) indicate that the rate of LA formation from DHA at $383 \mathrm{~K}$, a typical temperature for this reaction, could be matched using PAl at only $343 \mathrm{~K}$. Hence, continuous experiments were performed at these two temperatures. When Sn-MFI was operated in water (Fig. 8a) in a $24 \mathrm{~h}$ test, the loss of LA yield was limited to only $23 \%$ in the case of $\mathrm{PAl}$, as opposed to $75 \%$ when the reaction was performed using DHA. An even more pronounced difference in the deactivation pattern was noticed when methanol was used as the solvent (Fig. 8b). We have previously observed that, for the alcohol-based conversion of DHA, the 10-membered ring MFI zeolites suffer from much faster coking with respect to BEA zeolites featuring the larger 12-membered rings, which renders the catalyst almost inactive after $12 \mathrm{~h}$ on stream. Remarkably, at the lower temperature employed for the conversion of PAl, more than $40 \%$ of the initial activity of Sn-MFI was retained after use for $24 \mathrm{~h}$. An appreciable gain in stability was observed also in the case of [Sn]BEA.

\section{Conclusions}

In this study, we uncovered silver supported on alumina as a highly efficient catalyst for the oxidehydration of waste glycerol to pyruvaldehyde and the advantages of using this compound instead of dihydroxyacetone for the sustainable manufacture of lactic acid and methyl lactate. Silver was chosen amongst other transition metals thanks to its optimal reduction potential, which enabled high activity and selectivity. In contrast, metals with a more noble character were less active and those with a higher tendency to oxidise favoured the further oxidation of the product. A maximal pyruvaldehyde yield of $c a$. $65 \%$ was attained, which remained stable over $24 \mathrm{~h}$ on stream. Characterisation of the used catalyst evidenced the formation of an oxide layer at the surface of the metal nanoparticles, which was demonstrated by DFT to be the active surface for the dehydrogenation of the acetol molecule obtained by dehydration of glycerol. In fact, the reaction was found to be thermodynamically limited on metallic silver and kinetically hindered on a pure oxide phase, due to the higher activation energy of the proton abstraction and the more difficult regeneration of the oxidic sites. Finally, we confronted the use of pyruvaldehyde and dihydroxyacetone for the preparation of lactic acid and methyl lactate over tin zeolites. Remarkably, with the former substrate it was possible to achieve comparable rates at a $40 \mathrm{~K}$ lower reaction temperature, greatly reducing the deactivation of the stannosilicates. Accordingly, a glycerol to lactic acid process featuring pyruvaldehyde as intermediate is expected to bring substantial environmental and economic benefits compared to the best process currently envi- 
saged for the valorisation of this feedstock, which is based on the exploitation of dihydroxyacetone.

\section{Acknowledgements}

This work was sponsored by the Swiss National Science Foundation (Project Number 200020-159760). The Scientific Center for Optical and Electron Microscopy at ETH Zurich, ScopeM, is acknowledged for the use of their facilities. Dr S. Mitchell is thanked for the TEM measurements and Dr R. Hauert for the XPS analyses. Prof. N. López and R. García-Muelas are grateful to MINECO (CTQ2015-68770-R) for financial support and BSC-RES for providing generous computer resources.

\section{References}

1 (a) T. Werpy and G. R. Petersen, Top Value Added Chemicals from Biomass: Vol. I - Results of Screening for Potential Candidates from Sugars and Synthesis Gas, US DOE, 2004; (b) J. J. Bozell and G. R. Petersen, Green Chem., 2010, 12, 539-554; (c) R. E. Drumright, P. R. Gruber and D. E. Henton, Adv. Mater., 2000, 12, 1841-1846; (d) S. Cohen, T. Yoshioka, M. Lucarelli, L. Hwang and R. Langer, Pharm. Res., 1991, 8, 713-720; (e) J. C. SerranoRuiz, A. Pineda, A. M. Balu, R. Luque, J. M. Campelo, A. A. Romero and J. M. Ramos-Fernández, Catal. Today, 2012, 195, 162-168.

2 J. Lunt, Polym. Degrad. Stab., 1998, 59, 145-152.

3 M. Dusselier, P. Van Wouwe, A. Dewaele, E. Makshina and B. F. Sels, Energy Environ. Sci., 2013, 6, 1415-1442.

4 (a) R. Datta and M. Henry, J. Chem. Technol. Biotechnol., 2006, 81, 1119-1129; (b) Y.-J. Wee, J.-N. Kim and H.-W. Ryu, Food Technol. Biotechnol., 2006, 44, 163-172; (c) M. Singhvi, G. Gurjar, V. Gupta, D. Gokhale, et al., RSC Adv., 2015, 5, 2024.

5 D. T. Johnson and K. A. Taconi, Environ. Prog., 2007, 26, 338-348.

6 R. Ciriminna, C. Della Pina, M. Rossi and M. Pagliaro, Eur. J. Lipid Sci. Technol., 2014, 116, 1432-1439.

7 (a) P. Lakshmanan, P. P. Upare, N.-T. Le, Y. K. Hwang, D. W. Hwang, U.-H. Lee, H. R. Kim and J.-S. Chang, Appl. Catal., A, 2013, 468, 260-268; (b) Y. Shen, S. Zhang, H. Li, Y. Ren and H. Liu, Chem. - Eur. J., 2010, 16, 7368-7371; (c) H. J. Cho, C.-C. Chang and W. Fan, Green Chem., 2014, 16, 3428-3433.

8 (a) D. Hekmat, R. Bauer and J. Fricke, Bioprocess Biosyst. Eng., 2003, 26, 109-116; (b) G. M. Lari, C. Mondelli and J. Pérez-Ramírez, ACS Catal., 2015, 5, 1453-1461.

9 P. Y. Dapsens, C. Mondelli and J. Pérez-Ramírez, Chem. Soc. Rev., 2015, 44, 7025-7043.

10 C. M. Osmundsen, M. S. Holm, S. Dahl and E. Taarning, Proc. R. Soc. London, Ser. A, 2012, 468, 2000-2016.

11 F. de Clippel, M. Dusselier, R. Van Rompaey, P. Vanelderen, J. Dijkmans, E. Makshina, L. Giebeler, S. Oswald,
G. V. Baron, J. F. M. Denayer, P. P. Pescarmona, P. A. Jacobs and B. F. Sels, J. Am. Chem. Soc., 2012, 134, 10089-10101.

12 G. M. Lari, P. Y. Dapsens, D. Scholz, S. Mitchell, C. Mondelli and J. Pérez-Ramírez, Green Chem., 2016, 18, 1249-1260.

13 R. M. Ravenelle, F. Schuessler, A. D’Amico, N. Danilina, J. A. van Bokhoven, J. A. Lercher, C. W. Jones and C. Sievers, J. Phys. Chem. C, 2010, 114, 19582-19595.

14 P. T. Williams and S. Besler, Renewable Energy, 1996, 7, 233-250.

15 H. Baltes and E. I. Leupold, US Pat 4302609, 1981.

16 R. K. Pazhavelikkakath Purushothaman, J. van Haveren, I. Melián-Cabrera, E. R. H. van Eck and H. J. Heeres, ChemSusChem, 2014, 7, 1140-1147.

17 F. Auneau, S. Noël, G. Aubert, M. Besson, L. Djakovitch and C. Pinel, Catal. Commun., 2011, 16, 144-149.

18 A. H. Øygarden, J. Pérez-Ramírez, D. Waller, K. Schöffel and D. Brackenbury, WO 2004/110622, 2004.

19 P. Y. Dapsens, C. Mondelli, J. Jagielski, R. Hauert and J. Pérez-Ramírez, Catal. Sci. Technol., 2014, 4, 2302-2311.

20 S. Valencia and A. Corma, US Pat 5968473, 1999.

21 (a) G. Kresse and J. Furthmüller, Comput. Mater. Sci., 1996, 6, 15-50; (b) G. Kresse and J. Furthmüller, Phys. Rev. B: Condens. Matter, 1996, 54, 11169-11186.

22 B. Hammer, L. B. Hansen and J. K. Nørskov, Phys. Rev. B: Condens. Matter, 1999, 59, 7413-7421.

23 (a) P. E. Blöchl, Phys. Rev. B: Condens. Matter, 1994, 50, 17953; (b) G. Kresse and J. Joubert, Phys. Rev. B: Condens. Matter, 1999, 59, 1758.

24 (a) M. Schmid, A. Reicho, A. Stierle, I. Costina, J. Klikovits, P. Kostelnik, O. Dubay, G. Kresse, J. Gustafson, E. Lundgren, J. N. Andersen, H. Dosch and P. Varga, Phys. Rev. Lett., 2006, 96, 146102; (b) J. Schnadt, A. Michaelides, J. Knudsen, R. T. Vang, K. Reuter, E. Lægsgaard, M. Scheffler and F. Besenbacher, Phys. Rev. Lett., 2006, 96, 146101.

25 W. M. Haynes, CRC Handbook of Chemistry and Physics, CRC Press, Boca Raton, 96th edn, 2015.

26 H. J. Monkhorst and J. D. Pack, Phys. Rev. B: Solid State, 1976, 13, 5188-5192.

27 G. Makov and M. C. Payne, Phys. Rev. B: Condens. Matter, 1995, 51, 4014-4022.

28 (a) G. Henkelman and H. Jónsson, J. Chem. Phys., 2000, 113, 9978-9985; (b) G. Henkelman, B. P. Uberuaga and H. Jónsson, J. Chem. Phys., 2000, 113, 9901-9904.

29 (a) A. M. Ferraria, A. P. Carapeto and A. M. Botelho do Rego, Vacuum, 2012, 86, 1988-1991; (b) S. W. Gaarenstroom and N. Winograd, J. Chem. Phys., 1977, 67, 3500-3506.

30 M. Besson and P. Gallezot, Catal. Today, 2000, 57, 127-141.

31 Y. Kwon, S. C. S. Lai, P. Rodriguez and M. T. M. Koper, J. Am. Chem. Soc., 2011, 133, 6914-6917.

32 M. J. Gilkey, P. Panagiotopoulou, A. V. Mironenko, G. R. Jenness, D. G. Vlachos and B. Xu, ACS Catal., 2015, 5, 3988-3994.

33 J. P. Dever, K. F. George, W. C. Hoffman and H. Soo, Ethylene Oxide, in Kirk-Othmer Encyclopedia of Chemical Technology, John Wiley \& Sons, Inc., Hoboken, 2004, pp. 632-673. 